\title{
В память о Василии Ивановиче Каледине (1935-2020)
}

\author{
Н.А. Попова, В.П. Николин, И.А. Серова, Т.И. Меркулова凶
}

Для цитирования: Попова Н.А., Николин В.П., Серова И.А., Меркулова Т.И. В память о Василии Ивановиче Каледине (1935-2020). Письма в Вавиловский журнал генетики и селекции. 2020;6(3):156-158. DOI 10.18699/Letters2020-6-18

\section{In memoriam Vasiliy I. Kaledin (1935-2020)}

\author{
N.A. Popova, V.P. Nikolin, I.A. Serova, T.I. Merkulova $\bowtie$
}

For citation: Popova N.A., Nikolin V.P., Serova I.A., Merkulova T.I. In memoriam Vasiliy I. Kaledin (1935-2020). Pisma v Vavilovskii Zhurnal Genetiki $\mathrm{i}$ Selektsii = Letters to Vavilov Journal of Genetics and Breeding. 2020;6(3):156-158. DOI 10.18699/Letters2020-6-18 (in Russian)

И обещала жизнь нам долгий-долгий день... Гюнтер Тюрк, 1937 г.

29 мая 2020 г. ушел из жизни Василий Иванович Каледин, ведущий научный сотрудник лаборатории регуляции экспрессии генов Института цитологии и генетики Сибирского отделения Российской академии наук.

Семья Калединых была выслана во время кампании сплошной коллективизации в 1930 г. из Алтайского края в город Надым (Ямало-Ненецкий автономный округ). Чудом выжив в невыносимых условиях Заполярья, Калединым удалось перебраться в город Прокопьевск. Василий Иванович Каледин родился 15 октября 1935 г. в Прокопьевске. Кроме него, в семье было еще трое детей. После окончания школы Василий Иванович окончил два института, сельскохозяйственный и педагогический, в Барнауле. Далее была работа учителем математики и биологии в школе. Он рассказывал, что однажды прочитал статью Н.В. Тимофеева-Ресовского, которая его так впечатлила, что он решил непременно заниматься генетикой.

В 1965 г. В.И. Каледин был принят на работу в Институт цитологии и генетики СО АН СССР в лабораторию экспериментального мутагенеза на должность старшего лаборанта и в том же году поступил в аспирантуру в лабораторию генетики рака под руководством профессора Р.П. Мартыно- вой. В реферате, требуемом при поступлении в аспирантуру, В.И. Каледин изложил свои представления о патогенезе злокачественного роста клеток, включая концепцию эпигенетических механизмов возникновения злокачественных опухолей, которую он развивал всю свою жизнь в науке.

В то время, в начале 1960-х годов, среди онкологов доминирующим было представление о генотоксическом механизме действия химических канцерогенов, считалось совершенно очевидным, что мишенью действия канцерогенов является ДНК. Таким образом, канцерогенный эффект фактически сводился к мутагенному. Однако наряду с этим были высказывания и о возможной эпигенетической природе рака, в пользу которой свидетельствовал ряд фактов, не укладывающихся в генотоксическую теорию. Василий Иванович придерживался эпигенетической гипотезы, основанной на том, что опухолевый фенотип формируется вследствие нарушения молекулярных механизмов клеточной дифференцировки. Согласно этой гипотезе, первичное действие канцерогенов направлено не на генетический материал клетки-мишени, а на механизмы реализации генетической информации и, следовательно, заключается в нарушении регуляции экспрессии генов. При этом не от- 


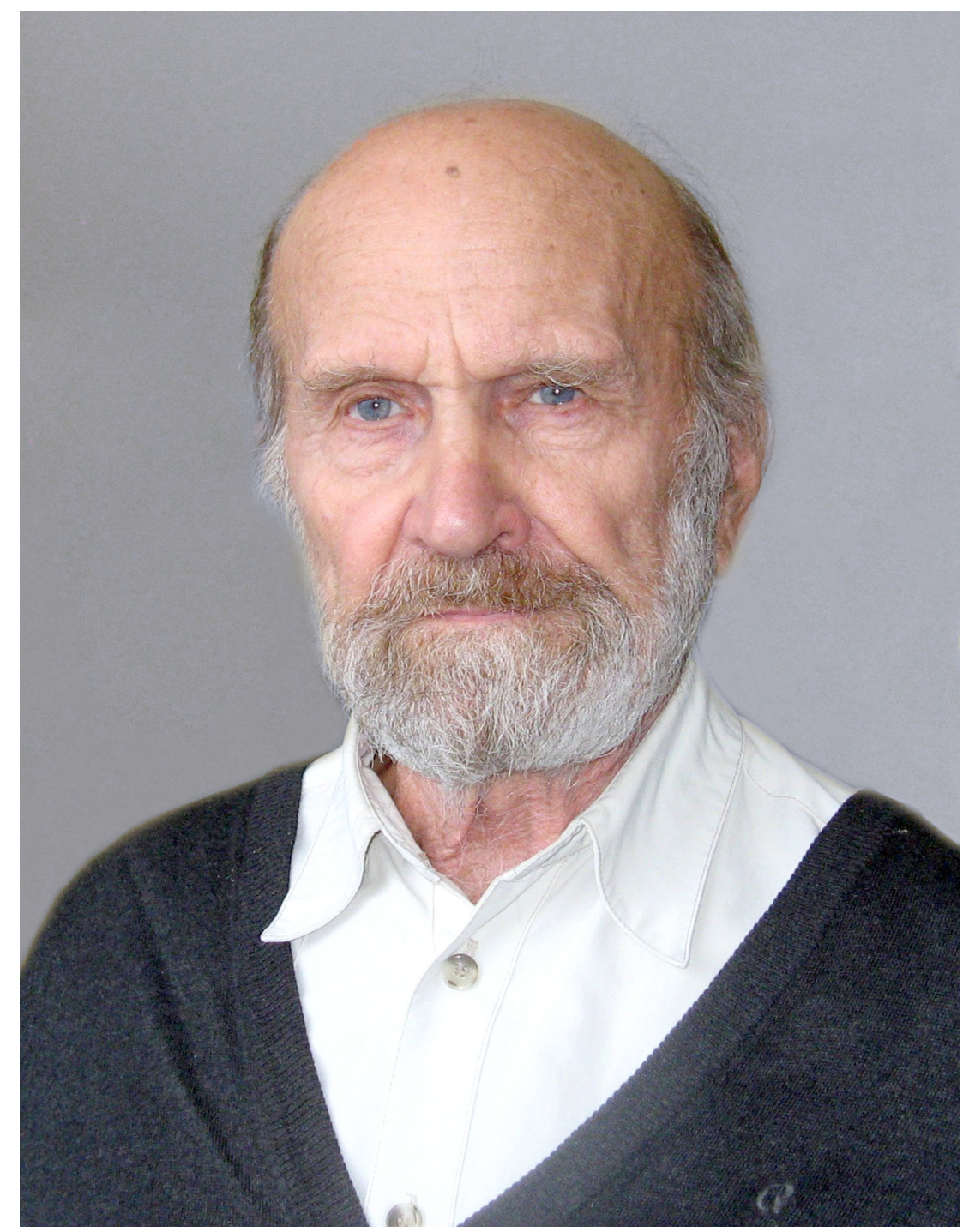

вергается мутагенный эффект, вносящий вклад в развитие многих опухолей и в ряде частных случаев являющийся его единственной причиной. Своими экспериментальными работами В.И. Каледин внес весомый вклад в подтверждение и развитие этой концепции. В 1971 г. им была защищена кандидатская диссертация «Биохимическое и иммунологическое изучение Н-белков печени животных, различающихся по чувствительности к канцерогенным аминоазокрасителям». Научными руководителями его работы были д.б.н. Р.П. Мартынова и д.б.н. Р.И. Салганик.

С начала работы Василия Ивановича в лаборатории генетики рака и до конца жизни им проведено значительное количество экспериментов, в которых были получены доказательства линейной, видовой и органной специфичности действия канцерогенов. Установлено, что: под влиянием канцерогенов у животных сначала появляются доброкачественные опухоли, а потом они малигнизируются; среди мышей инбредных линий можно выделить чувствительные и резистентные линии к определенным канцерогенам; канцерогенный и мутагенный эффекты могут быть не связаны; существуют неканцерогенные аналоги канцерогенов и немутагенные канцерогены. В ряде экспериментов было показано также, что один из ранних эффектов гепатоканцерогенных соединений - нарушение глюкокортикоидной индукции ключевого фермента метаболизма тирозина в печени - тирозинаминотрансферазы, причем только у чувствительных к этому канцерогену линий или видов грызунов. В другой серии экспериментов аналогичные данные были получены при изучении влияния печеночных канцерогенов на индукцию альфа-фетопротеина. Важно отметить, что наряду с изменением регуляции экспрессии генов наблюдались и изменения дифференцировки клеток в печени. Хотя в этих экспериментах не была доказана прямая связь наблюдаемых эффектов с канцерогенезом, не вызывало сомнений, что канцерогены избирательно вмешиваются в регуляцию экспрессии генов. Все эти результаты противоречат мутагенной теории канцерогенеза и хорошо укладываются в эпигенетическую. В этом цикле работ с Василием Ивановичем тесно сотрудничали Н.П. Захарова, Т.Т. Глазко и И.А. Серова.

Позднее в работе лаборатории регуляции экспрессии генов были обнаружены регуляторные белки, обеспечиваю- 
щие видовую и линейную специфичность действия гепатоканцерогенов: транскрипционные факторы семейства FoXA, необходимые для дифференцировки гепатоцитов, и конститутивный рецептор андростанов (CAR), являющийся одновременно рецептором ксенобиотиков и транскрипционным фактором. Оказалось, что гепатоканцерогенное для данного вида/линии вещество взаимодействует с CAR, который активируется и передает сигнал на FoXA, активность которого, наоборот, снижается. В итоге меняется экспрессия множества генов, в том числе повышается экспрессия генов, связанных с усилением пролиферации.

В.И. Каледин был организатором и других научных направлений в лаборатории генетики рака, прежде всего, связанных с разработкой экспериментальных методов повышения эффективности противоопухолевой терапии. Так, в 1980-х годах совместно с В.Г. Будкером (Новосибирский институт биоорганической химии СО АН СССР, ныне Институт химической биологии и фундаментальной медицины СО РАН) был проведен цикл работ по использованию липосом для адресной доставки химиопрепаратов в опухолевые и метастатические узлы.

При использовании свойства липосом в качестве корпускулярных частиц накапливаться при внутритканевом введении в регионарных лимфоузлах, а при внутривенном введении - в печени, удавалось вылечить до 60 \% животных от метастазов опухолей. Результаты были опубликованы в нескольких статьях в Journal National Cancer Institute. Условием публикации в этом престижном издании было признание результатов достоянием человечества без патентования. Следует отметить также и работы лаборатории генетики рака по воздействию на течение инфекционных заболеваний (туберкулеза) и рост злокачественных опухолей вакцины БЦЖ, стимулирующей макрофагальное звено иммунной защиты. В настоящее время, когда человечество все чаще сталкивается с инфекциями, вызываемыми быстро изменяющимися вирусами, которые «приходят и остаются», вновь актуален вопрос о стимуляции врожденной ветви иммунитета.

В последние годы жизни Василий Иванович руководил работами по повышению эффективности химиотерапии злокачественных опухолей генотоксическими противоопухолевыми агентами (Топотекан, Этопозид), проводимыми совместно с Институтом химической биологии и фундаментальной медицины СО РАН и Новосибирским институтом органической химии им. Н.Н. Ворожцова СО РАН. Показано, что в этом отношении перспективны синтезированные ингибиторы фермента репарации тирозил-ДНК-фосфодиэстеразы.

В.И. Каледин - автор и соавтор более трехсот научных работ, опубликованных в отечественной и зарубежной печати.

Василий Иванович хорошо знал и любил поэзию и сам писал стихи. Еще больше ему удавались пародии на стихи других поэтов. Он провел колоссальную работу для опубликования стихов репрессированного в годы сталинизма поэта Гюнтера Тюрка. Стихи были написаны Г. Тюрком во время скитаний по тюрьмам и лагерям и при жизни поэта не были опубликованы. Благодаря редакторской работе Василия Ивановича в 1997 г. вышел сборник стихов Г. Тюрка, современника и жертвы трагической эпохи в России.

Все, кто знал Василия Ивановича Каледина, сохранят память о нем - по-настоящему преданном науке ученом и добром, отзывчивом человеке.

Поступила в редакцию 01.06.2020. После рецензирования 29.06.2020. Принята к публикации 30.06.2020. 